This is not a peer-reviewed article.

Pp. 281-290 in Drainage VIII Proceedings of the Eighth International Symposium,

21-24 March 2004 (Sacramento, California USA), Publication Date 21 March 2004. ASAE Publication Number 701P0304, ed. R. Cooke.

\title{
COMParison OF DRAinMod BaSEd WATERShed SCALE Models
}

\author{
G. Fernandez, G.M. Chescheir, R.W. Skaggs, and D.M. Amatya ${ }^{1}$
}

\begin{abstract}
Watershed scale hydrology and water quality models (DRAINMOD-DUFLOW, DRAINMODW, DRAINMOD-GIS and WATGIS) that describe the nitrogen loadings at the outlet of poorly drained watersheds were examined with respect to their accuracy and uncertainty in model predictions. Latin Hypercube Sampling (LHS) was applied to determine the impact of uncertainty in estimating field exports and decay coefficients on the uncertainty of the simulated nitrogen loads at the outlet of a 2950 ha coastal plain watershed in eastern North Carolina. Mean daily flow predictions were all within $1 \%$ of the observed flows. Except for the WATGIS model, mean daily nitrate-nitrogen load predictions were within $2 \%$ of the observed load. Statistical test indicated no difference between the predictions of the different models. Uncertainty analysis indicated that uncertainty in quantifying the field exports has greater impact on the uncertainty of outlet loads than does the uncertainty associated with decay coefficient. The uncertainty of predicted outputs from the DRAINMOD-GIS and WATGIS models are similar.
\end{abstract}

\section{KEYWORDS. Drainage, BMP, Nitrogen, Watershed, DRAINMOD, Water Quality}

\section{INTRODUCTION}

Models of varying complexities have been developed for characterizing the effects of land and water management practices on the hydrology and water quality of watersheds with poorly drained soils. These models are based on a mechanistic field hydrology model, DRAINMOD (Skaggs, 1999), coupled with different approaches to route water and nitrogen loads from the field edge to the watershed outlet. The models range from the simplified, lumped parameter approaches that use export coefficients and delivery ratio concepts (Amatya et al., 2004; Fernandez et al., 2002) to more mechanistic and process-based models (Konhya and Skaggs, 1992; Amatya et al., 1999; Fernandez et al., 1997, 2000, 2001, 2004). The simplest model, WATGIS, (Fernandez et. al., 2002) uses export concentrations and delivery ratios to calculate the loadings at the outlet of the watershed. Another model, DRAINMOD-GIS, (Fernandez et. al., 2004b) uses a simplified transport model based on approximate solution of the diffusion equation. This model uses a spatially distributed response function to route water and loads from the field edge of contributing areas to the watershed outlet. On the other end of the spectrum are the more mechanistic models, DRAINMOD-DUFLOW and DRAINMOD-W (Fernandez et. al.,

\footnotetext{
${ }^{1}$ The authors are Glenn P. Fernandez, ASAE Member Engineer, Research Associate, Biological and Agricultural Engineering Department, North Carolina State University, Raleigh, NC; George M. Chescheir, P.E., ASAE Member Engineer, Research Assistant Professor, Biological and Agricultural Engineering Department, North Carolina State University, Raleigh, NC; R. Wayne Skaggs, P.E., ASAE Fellow Engineer, William Neal Reynolds and Distinguished University Professor, Biological and Agricultural Engineering Department, North Carolina State University, Raleigh, NC and Devendra M. Amatya, P.E., ASAE Member Engineer, Research Hydrologist, USDA Forest Service, Charleston, S.C. Corresponding Author: Glenn P. Fernandez, Box 7625, Biological and Agricultural Engineering Department, North Carolina State University, Raleigh, NC. Tel (919) 515 6714; email:gfernand@eos.ncsu.edu.
} 
2004a). These models use numerical solution to the Saint Venant equation combined with an ADR equation for pollutant transport and a flexible in-stream water quality model.

When coupled with uncertainty analysis component, these models are potentially useful tools for planning and decision making. Determination of uncertainties in model outputs is of great importance considering that there are inherent limitations of the models in describing the physical processes and the underlying uncertainties in model inputs and parameterization. The model parameters, boundary conditions, forcing functions, input variables, and other factors that are used in model simulations are generally not known with certainty (Melching et al., 2001). Generally, the uncertainty in model predictions is a function of uncertainties in model parameters, input data and model structure. It is often believed that a more comprehensive model is better able to simulate reality since the more complex the model, the more processes are described. However, in more comprehensive models, there will be more process parameters that need to be identified and quantified with certainty.

This paper presents a comparison of the accuracy of the different models in describing the hydrology and water quality processes of a coastal plain watershed with poorly drained soils. In addition, uncertainty analysis was used to compare the simplified models. The paper addresses the two aspect of adequacy of the models, namely accuracy and uncertainty in quantifying outflows and loads from a 2950 ha managed forest watershed in the lower coastal plain of eastern North Carolina.

\section{Watershed Scale Models}

A brief description of the individual models is given below and compared as shown in Table 1 . The reader is referred to the individual references for details.

Model 1. DRAINMOD-DUFLOW. DRAINMOD-DUFLOW (Fernandez et al., 2004a) is an integrated model that consists of the Dutch model DUFLOW (Aalderlink et al, 1995) and the field hydrology model DRAINMOD. Stream routing in DUFLOW uses a numerical solution to the St Venant equation for one-dimensional flow in open channels. The model also includes a water quality routine that uses a solution to the one-dimensional ADR transport equation. The instream nitrogen transformation is modeled by a lumped parameter exponential decay equation. However, DUFLOW is flexible in handling in-stream processes; it can be user specified.

Model 2. DRAINMOD-W. DRAINMOD-W (Fernandez et al., 2004a) is an integrated watershed scale model that consists of DRAINMOD field hydrology model and a stream routing model based on the one-dimensional solution to the St Venant equation and water quality sub-model based on solution to the ADR equation (Zheng et al, 2002). Similar to DRAINMOD-DUFLOW, field hydrology interacts with stream hydraulics but the level of interaction is on a daily basis.

Model 3. DRAINMOD-GIS. DRAINMOD-GIS (Fernandez et al., 2004b) is a linkage of the field hydrology model DRAINMOD and a generalized spatially distributed canal routing model using a response function (Olivera and Maidment, 1999). Field hydrology is simulated with DRAINMOD and the drainage network routing is through an impulse response function using a first passage time distribution for the time of travel in the flow path. This model uses a generalized approach to flow routing which considers spatially distributed inputs and parameters where drainage from contributing areas (non-overlapping) are considered separately instead of spatially averaged. A two parameter routing response function model (derived from first passage time distribution) was developed for each contributing area in which parameters are related to flow time (advective velocity) and shear effects (dispersion) along the flow path.

Model 4. WATGIS. WATGIS (Fernandez et al., 2002) is a Geographic Information System (GIS)-based, lumped parameter water quality model that was developed to estimate the spatial and temporal nitrogen loading patterns for lower coastal plain watersheds in eastern North 
Carolina. The model uses a spatially distributed delivery ratio (DR) parameter to account for nitrogen retention or loss along a drainage network. Delivery ratios are calculated from time of travel and an exponential decay model for in-stream dynamics. Travel times from any point in the drainage network to the watershed outlet are obtained from a regression model which expresses travel times as a nonlinear function of upstream contributing area, length of flow path and mean field drainage outflow. Nitrogen load from contributing areas in the watershed delivered to the main watershed outlet is obtained as the product of field export with the corresponding delivery ratio. The total watershed load at the outlet is the combined loading of the individual fields. Inputs to the model include exports from source areas that can either be measured or modeled, decay coefficient and the field parameters used in DRAINMOD.

Table 1. Models developed to predict hydrology and nutrient transport in drained watersheds.

\begin{tabular}{|c|l|l|l|l|l|l|l|c|}
\hline $\begin{array}{c}\text { MOD } \\
\text { NO }\end{array}$ & MODEL* & $\begin{array}{l}\text { CHANNEL } \\
\text { FLOW }\end{array}$ & $\begin{array}{l}\text { FEED- } \\
\text { BACK }\end{array}$ & $\begin{array}{l}\text { TRANS- } \\
\text { PORT }\end{array}$ & $\begin{array}{l}\text { WATER } \\
\text { QUAL. }\end{array}$ & $\begin{array}{l}\text { UNCERT. } \\
\text { ANALYS. }\end{array}$ & $\begin{array}{l}\text { GIS } \\
\text { RUNTIME } \\
\text { ONE-YR }\end{array}$ \\
\hline 2 & $\begin{array}{l}\text { DRAINMOD- } \\
\text { DUFLOW }\end{array}$ & ST VENANT & YES & ADR & $\begin{array}{l}\text { EXP } \\
\text { DECAY }\end{array}$ & & NO & 9 MIN \\
\hline 3 & $\begin{array}{l}\text { DRAINMOD- } \\
\text { GIS }\end{array}$ & $\begin{array}{l}\text { SIMPLIFIED } \\
\text { DIFFUSION }\end{array}$ & NO & $\begin{array}{l}\text { SLUG } \\
\text { FLOW }\end{array}$ & $\begin{array}{l}\text { EXP } \\
\text { DECAY }\end{array}$ & YES & YES & 1.5 MIN \\
\hline 4 & WATGIS & N/A & N/A & $\begin{array}{l}\text { SLUG } \\
\text { FLOW }\end{array}$ & $\begin{array}{l}\text { EXP } \\
\text { DECAY }\end{array}$ & YES & YES & 3 SEC \\
\hline
\end{tabular}

*All models use DRAINMOD to predict both surface and subsurface drainage rates at the field scale.

\section{Model Testing AND COMPARISONS}

Site Description. The study watershed is a 2950 ha drained managed forest watershed (S4 in Fig. 1) in eastern North Carolina. The soils of the watershed consist of both organic (primarily Belhaven and Pungo series) and mineral soils (poorly drained Portsmouth and Cape Fear series). The drainage system consists of field ditches which are $100 \mathrm{~m}$ apart leading to collector canals at about $800 \mathrm{~m}$ intervals which outlet to main canals about $1600 \mathrm{~m}$ (one-mile) apart. Surface cover of the watershed is characterized by second growth mixed hardwood and pine forest and loblolly pine plantation of various ages and stages (Weyerhaeuser, 1997).

Flow and drainage water for water quality were sampled from several gauging and sampling stations within the watershed (Fig. 1). Gauging stations are located at four field drainage outlets (F3, F5, F6 and F7), three on the main drainage canals (S1, S2, and S3) and one at the outlet of watershed (S4). Instrumentation at the automatic stations includes sharp crested $120^{\circ} \mathrm{V}$-notch weirs, water level recorders, automatic samplers and microprocessors to store data and control the samplers. Shelby (2002) presented a detailed description of the network of monitoring stations for flow and water quality sampling for this sub-watershed. 
Simulation. The site was modeled as 27 fields ranging in size from 46 to 205 ha (Fig 2) with the drainage network discretized into 46 canal segments. Fields were assumed homogenous with respect to soils, surface cover and water management practices. Field areas and stream lengths were obtained from field surveys. In the absence of measured soil water characteristics for all the fields, properties of the dominant soil series in each field were obtained from field measurements and published values.

Water quality data (nitrate-nitrogen) collected from 1996-2000 composite and grab samples from five experimental fields in the S4 watershed were used to generate the concentrations and export coefficients for the individual fields. A regression model was developed to estimate the nitrogen loadings at the field edge as a function of daily discharge and previous day loadings (Fernandez et al., 2004a).

Uncertainty Analysis. The stratified sampling approach, Latin Hypercube Sampling (LHS) (McKay 1988), that allows efficient estimation of the statistics of output was used to investigate the uncertainty of the predictions of the simplified lumped parameter models (DRAINMOD-GIS and WATGIS). In LHS, the probability distribution of each basic variable is subdivided into $N$ ranges each with a probability of occurrence equal to $1 / N$. Random values of the basic variables are generated such that each range is sampled only once. Output statistics and distributions of the output variables are approximated from the sample of $N$ output values. Using this approach in previous studies, Fernandez et al., (2000, 2001) showed that for drainage routing and water quality modeling using DRAINMOD-GIS and WATGIS, uncertainties in the decay coefficient and field export concentrations have greater impact on the uncertainty in simulated outlet loads. In this paper, we follow the procedure of performing uncertainty analysis using LHS as described by Salas et al., (1999):

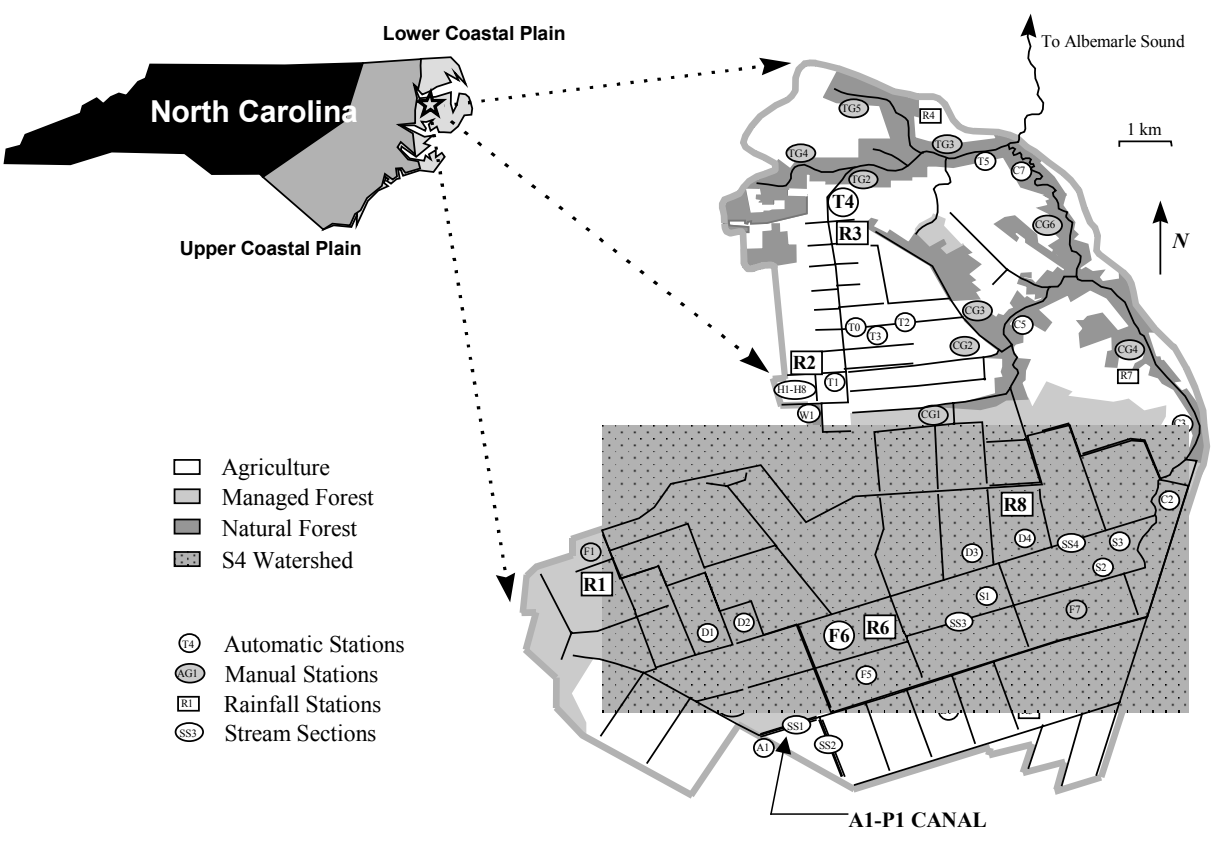

Figure 1. Schematic of the 10,000 ha study watershed near Plymouth in the NC coastal plain. 


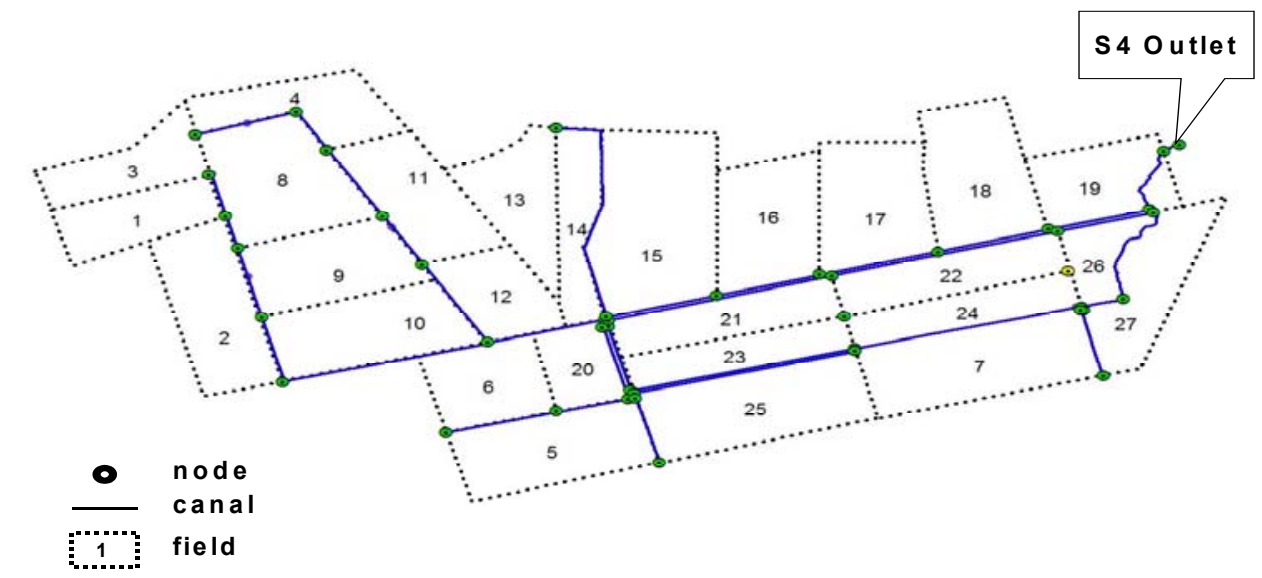

Figure 2. Schematic of field/canal/node network of S4 watershed (not drawn to scale).

1. For an input $x$, obtain $n$ uniform random numbers, $U_{1}, U_{2}, \ldots, U_{n}$ in the range of $0-1$.

2. Define $P_{i}=(1 / n)\left[U_{i}+(i-1)\right](i=1 \ldots n)$. Then the $P_{i}$ falls exactly within each of the $n$ intervals, $(0,1 / n),(1 n, 2 n) \ldots((n-1) / n, 1)$.

3. From the cumulative distribution function $F(x)$ of the input $x$, determine the values $x_{i}$ $=F^{-1}\left(P_{i}\right)(i=1, \ldots, n)$. Then $x=\left[x_{1}, x_{2}, \ldots, x_{n}\right]$ is the sample vector of the stochastic input $x$.

4. Perform random permutation of the set $\left(x_{1}, x_{2}, \ldots, x_{n}\right)$ obtained in step 3.

5. Repeat steps 1-4 for all inputs.

The procedure described above assumes that all inputs are independent. However, in the case of correlated inputs, the joint distributions of the inputs have to be considered. LHS was used to generate 500 random samples of several inputs parameters used in both models. The objective function are cumulative outflows and nitrate load at the watershed outlet. Mean, variances, coefficient of variations and the probability density functions for the model parameters were obtained from measured values at the watershed or estimated from literature. Having no evidence to the contrary, it was assumed that the parameters have negligible correlation. Results of the uncertainty analysis were summarized in the form of cumulative distributions of the objective function with corresponding confidence limits. Uncertainties in predicted outlet loads from both models were compared.

\section{Results and Discussion}

The main objective of the study was to compare the accuracy of the different models in predicting the outflow and nitrate-nitrogen loads from poorly drained watersheds. In addition to this, the uncertainty of predictions of the two simplified lumped parameter models,

DRAINMOD-GIS and WATGIS were compared. Flow and nitrate-nitrogen concentration data from 1996-1997 were used for calibration and data from 1998 to 2000 were used for the evaluation of the models. 
Simulations. For all models, predictions of the temporal trend and magnitude of monthly flows at the outlet of S4 agrees closely with the observed flows (Figure 3). Over the 2-year calibration period, the average error of prediction for all models is within $0.01 \mathrm{~mm} /$ day. Mean absolute error ranges from 0.2 to $0.5 \mathrm{~mm} /$ day. Except for WATGIS predictions, mean square errors for the three other models were less than 0.6. Percentage error was highest for WATGIS (-0.7\%) during the calibration period. Percentage errors for the other three models were within $0.3 \%$. Statistically, there is no difference in predictions errors of the four models at the $5 \%$ level of significance. In general, trends in daily predictions (not shown) indicate over-predictions especially during the passage of tropical storms (late summer to fall). However, the observed flows were probably underestimated because the weir at the outlet was submerged during these events. In WATGIS, the field outflows were not routed to the outlet (sum of outflows for all fields is the total outlet flow), hence, errors in flow prediction can be also attributed to neglecting the effects of routing the flow from the source areas to the outlet.

During the validation period, mean errors and absolute errors were within $0.01 \mathrm{~mm} /$ day and 0.35 $\mathrm{mm}$ /day, respectively. WATGIS has higher mean square error as compared to the other models. Percentage errors were within $1 \%$ for all models. Similar to the calibration period, errors in predictions of the different models are not statistically different at 5\% level of significance.

The monthly predicted $\mathrm{NO}_{3}-\mathrm{N}$ (nitrogen as nitrate) loads were also in good agreement with measured values as shown in Figure 3 (bottom graph). All models were minimally calibrated. Calibration was done by adjusting the exponential decay coefficient factor, $\mathrm{k}$, to optimize agreement of the predicted loads for the calibration period (1996-97). As shown in Table 2, mean prediction errors of DRAINMOD-W, DRAINMOD-DUFLOW and DRAINMOD-GIS are less than $1 \mathrm{~g} / \mathrm{ha} /$ day. On the other hand, the prediction error of WATGIS is slightly higher at 4 $\mathrm{g} / \mathrm{ha}$ /day which corresponds to a larger over-prediction of the cumulative load during the evaluation period (16\% as compared to less than $1.5 \%$ for the other models).

On a daily basis, the models under-predicted $\mathrm{NO}_{3}-\mathrm{N}$ loads at the outlet of $\mathrm{S} 4$ substantially in some years and over-predicted it in others. On a monthly basis, the agreement shown in Figure 3 would be considered excellent for multiple years on a watershed scale. The errors in prediction of the loads cannot be attributed solely to the errors in daily flow predictions. Errors in estimating export concentrations at the field edge through a regression equation would have contributed to the errors in the load predictions.

Uncertainty Analysis. The method used to determine the contribution of the input parameters to the variance in the objective functions (outlet flow, nitrogen load and mean delivery ratio) is the correlation structure between the parameters and the objective functions (Haan, 2000). The contribution, $F_{i}$, of an input parameter to the variability of the objective function was determined by

$$
F_{i}=\frac{r_{o, i}^{2}}{\sum_{i=1}^{p} r_{o, i}^{2}}
$$

where $r_{o}, i$ is the correlation between the objective function and the $i^{t h}$ parameter and $p$ is the number of uncertain parameters. Table 3 shows the relative contribution of each parameter to the variability in the objective functions. For both the WATGIS and DRAINMOD-GIS models, the parameter that quantifies stream dynamics, travel-time and velocity, contributed significantly to the variance in outlet flows. Field parameters such as the maximum surface storage (STMAX) and the hydraulic conductivities (CONK1 and CONK2) have less impact on the variability of outlet flows. These parameters were found to significantly impact the variability of field outflows (Haan, 2000). However, their impact on watershed outflow were modulated considering the stream hydraulics. 
The decay coefficient (KCOEFF), export concentrations (EXPORT) and canal velocities/travel time (VELOC/TRAVEL TIME) contributed significantly to the variance in outlet load and mean watershed delivery ratio. In general, uncertainty in estimating the field exports contributed significantly to the uncertainty in predicted watershed outlet load. However, the impact of uncertainty in decay coefficient cannot be neglected. Statistically, there is not much difference in the uncertainty effects of the parameters for both models.

\section{SUMMARY \& CONCLUSION}

Four watershed scale hydrology and water quality models were evaluated to determine their accuracy in estimating watershed outflows and nitrogen loads. In addition, the impacts of uncertainty in model parameters on the predicted watershed outflows and load were investigated for two models, WATGIS and DRAINMOD-GIS. For all models, the predicted watershed outflows were within $1 \%$ of the observed flows. Predicted nitrate-nitrogen loads were within $4 \%$ except for WATGIS where the percentage error is as large as $16 \%$. Overall, the models adequately simulated the watershed outflows. Although the predictions for nitrate-nitrogen loads were similar for all models, the simulations using the S4 watershed is not a rigorous test for the nitrogen loadings. The different models did not simulate the details of the field water quality processes. With the same field exports and minimal difference in predictions of the hydrology and hydraulics, it is expected that nitrogen loadings at the outlet would be similar.

Uncertainty analysis indicated that three parameters significantly impact the uncertainty in predicted watershed load. To reduce the uncertainty in load predictions and mean watershed delivery ratio, field exports and decay coefficient have to be estimated with greater certainty. This is in addition to accurate representation of the stream hydraulics.

With regards to the models, DRAINMOD-GIS appears to be a better model than WATGIS. DRAINMOD-GIS is more accurate than WATGIS in predicting outflows and nitrate loads, although the uncertainty of the predictions are similar to WATGIS. DRAINMOD-GIS uses a simplified routing model, hence, travel times along the drainage network are better estimated than the simple regression use in WATGIS.

\section{Acknowledgements}

This work was made possible by the support of USDA-CSRS Project No 98-35102-6493, EPA 319 Project and Weyerhaeuser Company. The authors would like to acknowledge the contributions Joe Bergman and Cliff Tyson of Weyerhaeuser and Wilson Huntley and Jay Frick of North Carolina State University for their assistance in obtaining field data. 
Table 2. Statistics for model predictions of outflow (Top) and nitrate-nitrogen loads (bottom) at S4.

\begin{tabular}{|l|c|c|c|c|}
\hline \multicolumn{1}{|c|}{ OUTFLOW } & DRAINMOD-W & $\begin{array}{c}\text { DRAINMOD- } \\
\text { DUFLOW }\end{array}$ & $\begin{array}{c}\text { DRAINMOD- } \\
\text { GIS }\end{array}$ & WATGIS \\
\hline \multicolumn{5}{|c|}{ Calibration 1996-1997 } \\
\hline Mean Error, mm/day & 0.014 & 0.004 & -0.006 & -0.005 \\
\hline Mean Abs Error, mm/day & 0.322 & 0.389 & 0.216 & 0.474 \\
\hline Mean Square Error & 0.356 & 0.543 & 0.247 & 1.974 \\
\hline Percentage Error, \% & $-0.13 \%$ & $0.01 \%$ & $0.25 \%$ & $-0.70 \%$ \\
\hline \multicolumn{7}{|c|}{ Prediction $\mathbf{1 9 9 8 - 2 0 0 0}$} \\
\hline Mean Error & -0.002 & 0.003 & -0.008 & -0.011 \\
\hline Mean Abs Error & 0.335 & 0.353 & 0.315 & 0.382 \\
\hline Mean Square Error & 0.451 & 0.603 & 0.653 & 1.012 \\
\hline Percentage Error, \% & $-0.8 \%$ & $0.4 \%$ & $-0.7 \%$ & $-0.8 \%$ \\
\hline
\end{tabular}

\begin{tabular}{|l|c|c|c|c|}
\hline \multicolumn{1}{|c|}{ NO $_{3}$-N LOAD } & DRAINMOD-W & $\begin{array}{c}\text { DRAINMOD- } \\
\text { DUFLOW }\end{array}$ & $\begin{array}{c}\text { DRAINMOD- } \\
\text { GIS }\end{array}$ & WATGIS \\
\hline \multicolumn{5}{|c|}{ Calibration 1996-1997 } \\
\hline Mean Error, kg/ha & $<0.001$ & $<0.001$ & -0.001 & -0.001 \\
\hline Mean Abs Error, kg/ha & 0.018 & 0.018 & 0.006 & 0.012 \\
\hline Mean Square Error & 0.002 & 0.002 & $<0.001$ & 0.002 \\
\hline Percentage Error, \% & $<0.1 \%$ & $0.4 \%$ & $-2.9 \%$ & $-3.5 \%$ \\
\hline \multicolumn{7}{|c|}{ Prediction $\mathbf{1 9 9 8 - 2 0 0 0}$} \\
\hline Mean Error, kg/ha & $<0.001$ & $<0.001$ & $<0.001$ & 0.004 \\
\hline Mean Abs Error, kg/ha & 0.019 & 0.018 & 0.009 & 0.013 \\
\hline Mean Square Error & 0.003 & 0.002 & 0.001 & 0.003 \\
\hline Percentage Error, \% & $0.48 \%$ & $1.4 \%$ & $1.2 \%$ & $16.4 \%$ \\
\hline
\end{tabular}

Table 3. Relative contribution $(\%), F_{i}$, of each parameter to the variance in objective functions.

\begin{tabular}{|l|c|c|c|c|c|c|}
\hline & $\begin{array}{c}\text { Table 3. Relative contribution (\%), } \boldsymbol{F}_{\boldsymbol{i}} \text {, of each parameter to the variance in objective functions. } \\
\text { GIS }\end{array}$ & \multicolumn{2}{|c|}{ Flow } & $\begin{array}{c}\text { WATGIS } \\
\text { DRAINMOD- } \\
\text { GIS }\end{array}$ & $\begin{array}{c}\text { WATGIS } \\
\text { DRAINMOD- } \\
\text { GIS }\end{array}$ & WATGIS \\
\hline & & & \multicolumn{2}{c|}{ Load } & \multicolumn{2}{c|}{ Delivery Ratio } \\
\hline KCOEFF & & & 19.3 & 21.5 & 26.3 & 29.6 \\
\hline EXPORT & & 34.2 & 40.4 & 26.5 & 32.3 \\
\hline VELOC/TRAVEL TIME & 83.6 & 84.0 & 42.7 & 34.0 & 43.0 & 34.6 \\
\hline DISPERSION & 9.4 & & 0.4 & & 1.0 & \\
\hline STMAX & 1.7 & 5.0 & 0.8 & 1.7 & 0.9 & 1.5 \\
\hline CONK, LAYER 1 & 2.1 & 3.2 & 1.2 & 1.1 & 1.2 & 1.0 \\
\hline CONK, LAYER 2 & 3.3 & 7.9 & 1.4 & 1.3 & 1.1 & 1.0 \\
\hline Total & 100 & 100 & 100 & 100 & 100 & 100 \\
\hline
\end{tabular}



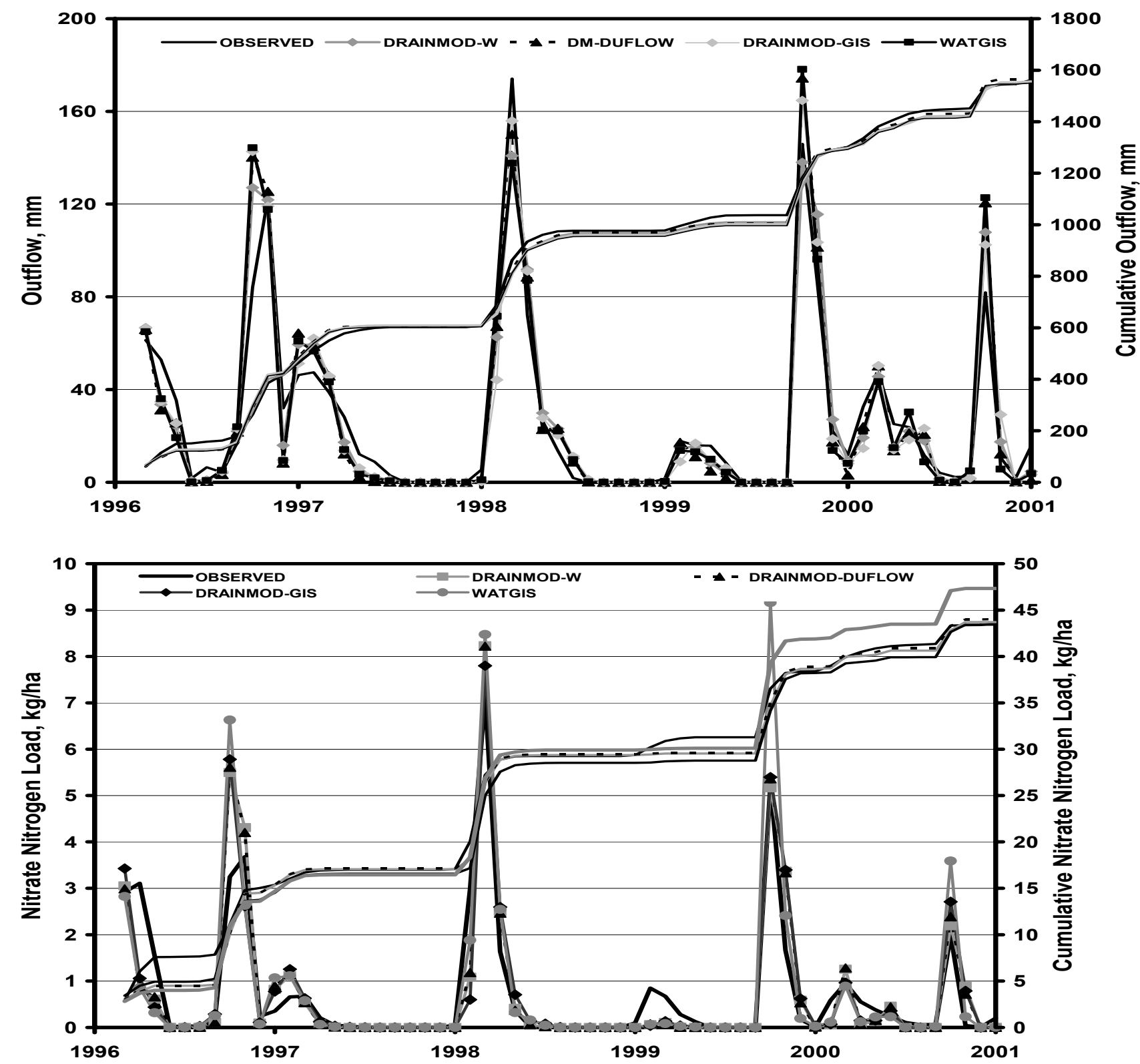

Figure 3. Predicted and measured outflows (top) and nitrate nitrogen loads (bottom) for the forested watershed, $\mathbf{S 4}$.

\section{REFERENCES}

Aalderink, R.H., NJ Klaver, and R. Noorman. 1995. DUFLOW V2.0 Microcomputer package for the simulation of 1-D flow and water quality in a network of open channels", In Proc. Inter. Symp. On Water Quality Modeling, Orlando, FL, 416-425.

Amatya, D.M.., G.M Chescheir, G.P Fernandez, RW Skaggs, and J.W. Gilliam. 2004.

DRAINWAT-based methods for estimating $\mathrm{N}$ transport on poorly drained watersheds, Trans ASAE (in press).

Amatya, D.M.., G.M.Chescheir, GP Fernandez and RW Skaggs. 1999. Testing of a watershed scale hydrologic/water quality model for poorly drained soils. In K.W. King, ed., Proceedings of the Mini-Conference, Advances in Water Quality Modeling:33-39, St. Joseph, MI, ASAE

Fernandez, G.P., G.M. Chescheir, R.W. Skaggs, and D.M. Amatya. 2004a. Models for predicting hydrology and nitrogen losses from poorly drained watersheds. Trans of ASAE, in review. 
Fernandez, G.P., R.W.Skaggs , G.M. Chescheir, and D.M. Amatya. 2004b. DRAINMOD-GIS: A lumped parameter watershed scale water quality model. Journ of Agric Water Management, in review.

Fernandez, G.P., G.M. Chescheir, R.W. Skaggs, D.M. Amatya, F. Birgand, and J.W. Gilliam. 1997. Development and field testing of a DRAINMOD based watershed scale model. ASAE Paper No 972194, ASAE. St. Joseph. MI.

Fernandez, G.P., G.M. Chescheir, D.M. Amatya, and R.W. Skaggs. 2000. Uncertainty in watershed scale drainage modeling: Implications for water quality modeling. ASAE Paper No 002095, ASAE. St. Joseph. MI.

Fernandez, G.P., R.W.Skaggs , G.M. Chescheir, and D.M. Amatya. 2001. WATMOD: An integrated watershed scale hydrology and water quality model. ASAE P. 012082, St. Joe, MI.

Fernandez, G.P., R.W. Skaggs, G.M. Chescheir and D.M. Amatya. 2002. WATGIS: A GIS-Based Lumped Parameter Water Quality Model, Transactions of ASAE. Vol 45(3):593-600.

Haan, P. 2000. The effect of parameter uncertainty on DRAINMOD predictions for hydrology, yield and water quality. Unpublished PhD Dissertation. North Carolina State University, Raleigh, NC.

Konyha, K.D. and R.W. Skaggs. (1992). A Coupled, field hydrology - open channel flow model: Theory. Trans. ASAE, 35(5): 1431-1440.

McKay, M.D. 1988. Sensitivity and uncertainty analysis using a statistical sample of input values. Uncertainty Analysis, Y. Ronen (ed). CRC, Boca Raton, FL., 145-186.

Melching, C.S., and C.G. Yoon. 1996. Key sources of uncertainty in QUAL2E Model of the Passaic River. Journal of Water Resources Planning and Management, vol. 122(2).

Olivera, , F. and D. Maidment . 1999. GIS based spatially distributed model for runoff routing. Water Resources Research, 35:1155-1164.

Salas, J.D. and H. Shin. 1999. Uncertainty Analysis of Reservoir Sedimentation. Journal of Hydraulic Engineering. v125(4).

Skaggs, R.W. 1999. Drainage Simulation Models. In: R.W. Skaggs and J.van Schilfgaarde (eds), Agr. Mono. 38, Agricultural Drainage, pp 469-536, Am. Soc.of Agr. Madison, WI.

Youssef, M.A. 2003. Modeling nitrogen transport and transformations in high water table soils. PhD Dissertation, N.C. State University, Raleigh, NC. 270p.

Zheng, C. and G.D. Bennett. 2002. Applied Contaminant Transport Modeling. Wiley Interscience. New York, NY. 